\title{
Early years ability grouping and the pedagogical constraints upon children's learning identities.
}

Dr. Guy Roberts-Holmes and Dr. Eleanor Kitto, Department of Learning and Leadership, UCL Institute of Education. University College London, Gower Street, London, WC1E 6BT

Key Words: pedagogy, ability grouping, learner identities.

$1^{\text {st }}$ submitted $26^{\text {th }}$ September 2018

\begin{abstract}
Despite research demonstrating that attainment-based grouping has little, if any, overall benefits there is an increasing trend towards ability grouping in the early years. Using an ethnographic case study the article demonstrates how different pedagogical approaches are used with different 'ability' groups. The pedagogical experiences of children, especially within 'low' ability groups potentially limits children's exposure to the tools required for successful participation in school. This varied pedagogy serves to govern, limit and constrain some young children's aspirations and expectations and operates as a self-fulfilling prophecy. When perception of 'ability' is seen as fixed, it influences the interactional experiences of children within different groups which, consequently, enhances or contrains children's future participation in school activity. The article concludes by suggesting that early years ability grouping needs to be contested and alternative pedagogies tried. This requires a reduction in 'high stakes' performance data and trust placed in early years teachers' pedagogical decision making processes.
\end{abstract}

\section{Introduction}

Despite research demonstrating that attainment-based grouping has little, if any, overall benefit in terms of student outcomes' (Taylor et al. 2016:2) there is an increasing trend towards ability grouping in the early years (Bradbury and Roberts-Holmes, 2018). Ability grouping and labelling tends to encourage teachers' entity theories which views ability as fixed leading to pedagogy confirming stereotypes and traits, whereas incremental theorists, who view human attributes as malleable, tend to focus on stereo-type disconfirming traits (Plaks et al., 2001). This, perception of ability as fixed, it is argued, influences the interactional experiences of children within different groups which, consequently, enhances or contrains children's future participation in school activity. If, as from a socio-cultural perspective, learning is embedded within the transaction between past and present experiences through mechanisms of interpersonal interaction, which support, and are supported by, the co-construction of meaning (Vygotsky, 1978, 1986; Wertsch, 1985, 1991; Wood et al., 1976; Mercer, 1995, 2000, 2008), then, it is suggested, that grouping practices can have enabling, or disabling, influences on participation through differences between the valued behaviour across social spheres (Wenger, 1998; Lave \& Wenger, 1991; Rogoff, 2008; Bourdieu \& Passeron, 1990). Bourdieu (1991) explicated how the use of specific forms of language is legitimised within specific fields and competent users of the valued language are consequently positioned more favourably within the field thus reaffirming the legitimacy. Wenger (1998) emphasised that it is through participation in cultural practices that individuals become increasingly familiar with the associated cultural tools of the practice. Therefore, the pedagogical 
experiences of children within different groups, potentially limit children's exposure to the tools required for continued participation in school. Furthermore, Wenger (2008) explored how identity emerges through social interaction and is continually negotiated within participation in different practices. Movement along the variety of trajectories in communities, entails transformations of identity based on negotiating conceptions of competence and relational positions of the 'self'. Through differing familiarities with the constituent skills required for participation, children experience differing perceptions of their competence within school activity.

Boaler (2005:141) has noted how ability grouping can act as a 'psychological prison' that 'breaks ambition' and 'almost formally labels kids as stupid' because labelling and grouping, even in the early years of school, serves to internalize children's own understandings of their so-called 'abilities'. Here ability grouping works to control and limit children's subjectivities and identities according to school defined 'ability' groups which this article argues has the potential to limit learning, by placing a ceiling on what children are expected to achieve (Bradbury and RobertsHolmes, 2018). Within the primary school context, Ireson and Hallam (2001:61) have suggested that grouping affects 'pupils' self-esteem, academic self-concept and their emotional responses to school'. Similarly, Marks (2013:35) has noted how in primary classrooms 'pupils took on, and saw themselves in terms of, group identifiers'. Porath and Bruner (2000) have shown how teachers' misinformed 'folk pedagogy' based upon children's abilities has detrimental consequences for children.

\section{Methodology}

The vignettes presented below were part of an ethnographic case study undertaken by a teacherresearcher, within a Year One classroom (children aged 5 and 6 years old) in a single form entry Primary School. The ethnographic research was carried out over one complete academic year and focused on the impact of the classroom grouping practices upon the children. The data comprised of documentation, field notes, a research diary, semi-structured interviews and classroom observations using video recording equipment. This ethnographic case study approach and data collection techniques were designed to accumulate detailed data on the pedagogical relationships within the different 'ability' groups. The research foregrounded six focus children to explore their experiences, activity and interactions within the class whilst grouped by 'ability'. The research also considered broader influences upon the grouping practices, by exploring the contextual features of the school, and the factors which propagated ability grouping.

Consents were obtained from all participants and the research was carried out with full regard for the 'Ethical Guidelines for Educational Research' (BERA, 2011). As an ethnographic case study undertaken by a teacher-researcher, there were ethical challenges relating to conflicting priorities between the different roles. Whilst the 'insider' nature of this research approach enabled access to the interconnected, contextualised, influences upon practice, and full access to the experiences of the focus children, there were also potential dilemmas in objectivity when obtaining and scrutinising data.

The ethnographic research school had been placed into 'special measures' following a recent Ofsted inspection and partly as a consequence, was in the process of being converted to an Academy at the time of the research. The substantive headteacher was absent from her post, as was the deputy headteacher. An acting headteacher was appointed temporarily, to support the 
transition to becoming an academy. In addition, three of the teachers from the seven classes, left their posts during the year, and were replaced by a series of short-term and long-term supply teachers. Four Teaching Assistants (TAs) also left their posts and only two of these posts were replaced by extending the roles of existing staff. The instability in staffing was attributed to the Ofsted grading and the prospect of forced academisation. The staffing changes also contributed to a rapid implementation of new policies, including a Teaching and Learning policy which stipulated that ability grouping would be applied to all classes for all Literacy and Numeracy lessons across the school, and that an adult would always work with the low ability groups. The rationale for this was that grouping children by ability would facilitate the teachers to accurately attend to the differing learning needs within their classes, and that the precence of an adult would enable the lowest attainers to make the necessary progress. The assumptions upon which this rationale was premised however, did not appear to be supported during the research. Contrary to the supposition that ability grouping would enable staff to more acutely attune to differing learning needs, the findings of the research suggests that it may have inadvertently restricted children's experiences and perpetuated low attainment.

\section{Findings}

\section{Ability grouping, pedagogy and self-fulfilling prophecies}

The following detailed vignettes from within the year one case study school demonstrated different staffing arrangements and pedagogies operating within each of the low, middle and high ability groups. The pedagogy varied depending upon the ability group and it is argued had the effect of confirming and controlling children's varied learning identities depending upon which ability group they were assigned to. Each vignette discusses how the varied pedagogical approaches had a tendency to set up children with internalised glass ceilings and limitations. This it is tentatively suggested might inadvertently lead to self-fulfilling expectations, lowered expectations and reduced aspirations.

The following vignettes provide a snapshot observation of the same class activity in each of the three different ability groups. Each group was observed within the same lesson to explore whether there were consequences to the grouping, and the allocation of adults, on the children's interactions and experiences. The vignettes focus upon a class writing activity which followed from a practical planting activity in which the children had each planted a seed. Within the observed lesson, the children had been tasked with writing an account of how they had planted their seed. They were focussing on sequencing each aspect of the activity and including time connectives. The children had worked in pairs on some shared composition and shared writing.

Example interaction during Literacy lesson, with 'low ability' group, supported by class TA (This excerpt is from the start of the group activity. Children are seated around a table, they each have their own Literacy book as well as phoneme cards, pencils, whiteboards and pens that are in the centre of the table).

TA- Right, looking and listening, let me see that you're ready. (TA exaggerates sitting up straight and widens eyes). So, David, what was the first thing that you did when you planted your seed?

David- I got a pot. 
TA-Ok. So 'first I got a pot'. What sound can you hear? What are you going to write first?

David - ' $f f^{\prime} f f^{\prime}$ ir'.

TA- That's itf, ir, s, $t$ (segments word into phonemes). So what letters do you need? (Shows phoneme card).

David- (Points to ' $\mathrm{f}$ '). Then....... is it 'e, $r$ '?

TA- No its 'I'. 'eff, igh, ar, es, tee' 'first'. Do you want me to write it for you? Here (takes whiteboard from table centre). What was your whole sentence?

David - Um. I got a pot.

TA -'First I got a pot'. There you go. (Writing on whiteboard)

TA - Bobby, what are you going to write?

Bobby - First I got a pot.

TA - No, think of your own idea.

Bobby - Err, I put mud in.

TA - No, what did you do first?

Bobby - Err, I got a pot.

TA- Ok, how do you write 'I'?

Bobby-(Looks at David's writing and forms 'I' in the air).

TA - Don't just copy, think about it yourself. (Bobby draws 'I' again in the air. Looks again at David's writing 'g, o, t').

TA - Come on, try to work it out by yourself. Don't just copy. Come and sit over here, and let David get on. (TA moves Bobby to another seat, further away from David).

In the above, the TA retains disciplinary control over the focus of the discussion, the progression of the activity and the conceptions of acceptable behaviour within the activity. She initially asks David a direct question, then restates his response, with the inclusion of the additional information that she considered appropriate for the completion of the task. She proceeds to pose the same questions to Bobby, but when Bobby gave the same response as that which was 'a correct response' during her discussion with David, it becomes an 'incorrect response' during her discussion with Bobby. The above pedagogy may, in part, account for the negative relationship between the amount of support and the children's academic progress outlined by Blatchford et al. (2011). If in the low ability group, the children are not given the opportunity to express their understanding then they are not able to exhibit the behaviour and activity that would enable their progression through the attainment criteria. Consequently, the TA's focus on task completion, potentially, was constraining the attainment level that her presence was intended to improve.

It is notable in the above vignette that the low ability group was assigned the Teaching Assistant. The use of such support staff has been seen to either have no effect or to negatively correlate to increased attainment (Muijs \& Reynolds, 2003; Blatchford et al., 2009a; Batchford et al., 2009b; 
Webster et al., 2011). Explanations for this have centred on children's decreased contact with teachers as a consequence of their increased contact with TAs, (Blatchford et al., 2009b), TA support of activities tending to be product focussed rather than process focussed (Blatchford et al., 2011), and TA preparedness in terms of subject knowledge and pedagogical understanding (Webster et al., 2011). Each explanation suggests that the increased use of support staff, potentially, results in limiting the educational experiences of the children that their presence is intended to enhance.

In contrast to the low ability group's restricted use of peers as a source of support for writing, the following example demonstrates that the 'middle ability' group freely use peers as a model, or prompt, for their writing, potentially enabling Arthur to progress in the activity further than he would have been able to independently.

Example interaction during Literacy lesson, with 'middle ability' group, working independently This excerpt is towards the end of the group activity.

Children are seated around a table, they each have their own Literacy book as well as phoneme cards and pencils.

Arthur - How do you do 'after'?

Child A - 'ar', 'f', 't', 'er'. (Picks up phoneme card). Look 'ar', 'f', 't', 'er' (Pointing to each picture on phoneme rainbow).

Arthur-Thanks.

Child A- Did you write 'after that'? I've used 'next', 'then', I'm gonna use 'after that' next.

Arthur - For the water? You using 'after that' for the water? (Looking at Child A's work).

Child A - Yep.

Arthur - Me too! (Laughs) What you doing for the mud one?

Child A - I've done that one! (Holding up work and pointing I did 'then').

Arthur -Me too! What one are you using then? After the 'after that' one? (Holding up work and pointing).

Child B - 'Finally'. You use 'finally' for the end one. If it's your end one, you use 'finally'.

Child A - 'Finally', yeah, it's the 'finally' one.

Arthur - Me too. I'm doing 'finally' for the end one. (Looking at Child A's work, which had large full-stops on, Arthur goes back and puts dots on each line of writing).

Arthur - (To child B) Have you done full-stops?

Child B- Yeah (Holds up writing).

Arthur - Me too look (Holds up writing). 
From this excerpt, during the same lesson, Arthur freely uses other children to support his own writing. He directly asks others for help and also uses their work as a model for his own, using another child's full stops, to prompt the inclusion of full stops in his own writing. From these vignettes notable differences were seen in relation to the children's opportunity to use each other as a source of support for their activity within each of the different ability groups. In considering this in relation to Vygotskian (1978) perspectives on the role of 'more experienced other' in mediating development, by restricting the 'more able other' solely to the adult within the activity, the children from the 'low ability' group were given less opportunity to play a role in negotiating and meeting their own learning needs. By the adult setting the parameters of the space between the child's independent capability and the support needed to progress further, she is potentially limiting the scope of his activity. Whereas, the freedom within the middle group, afforded a degree of learner agency, enabled Arthur to determine, and meet, his own support for his learning. In addition to the relative freedom within the middle ability group, for using each other to support their activity, there were also differences in the freedom for engaging in non-task related conversation experienced by each of the ability groups. This was particularly notable by contrasting the interaction between the children within the 'high ability' group, from the interaction within the 'low ability' group.

Example interaction during Literacy lesson, with 'high ability' group, working independently This excerpt is towards the middle of the group activity. Children are seated around a table, they each have their own Literacy book as well as phoneme cards and pencils.

Christopher - Did you do a bean or a sunflower?

Child C - Sunflower.

Christopher - I did a sunflower, I've done one before. I've got a picture from when I was a baby standing next to a massive one. It's taller than my dad, about up to the ceiling here.

Child D - I did a bean. I've done a sunflower before, it was so tall.

Lilly - I did a bean. Which one is yours? (Looks to group of seed pots).

Child D - (Gets up and gets seed pot). It's not growing yet, I've got zig-zags on my name though. (Goes to put seed back). Which one's yours?

Lilly - (Pointing). It is the one at the front. I drew Jack from Jack and the beanstalk on it (laughs).

Child D - (Laughing). That's clever. I don't think mine will grow. We did cress in class 1. Mine was the worst one.

Christopher - (Laughing) I remember that it was hair for the face but my eyes kept falling off!!

In considering exposure to, and participation in, particular linguistic activity as a catalyst for developing dialogic conventions, as well as for interpretation and negotiation of meaning, then the type of talk and the use of language experienced by the children within class has an impact upon their individual development (Mercer 2008). For example, within the discussion by the 'high ability' group, the children have opportunity to use language for different social purposes. They refer back to previous shared experiences, and they explain their individual experiences and activity. Whereas, any discussion amongst the 'low ability' children that was deemed to not be 
focused upon the relevant task, was stopped, or re-directed, by an adult. Although, not suggesting that all non-task-related conversation is therefore unequivocally beneficial, from the example of the 'high ability' group within this task, there are examples of language use which may have specific benefits for participation in school, which was restricted for the 'low ability' group. Firstly, is the opportunity for engaging in exploratory language use; the children use questions and explanations to refer to previous shared and individual experiences. In taking the argument that the use of language for explicit explanations and interrogations provide both opportunity for 'more accurate' understanding, or greater shared meaning, then opportunity to both experience and participate in this form of dialogue, potentially benefits future participation and shared understanding (Mercer, 2000). In addition, in relation to the assessment practices used by the school, exposure to, and experience of, exploratory talk offers access to the linguistic forms that enable individual understanding to be expressed in ways recognised within the school. Furthermore, within this example the children were increasing their social familiarity of each other, engaging in conversation for developing social relationships, and potentially increasing understanding upon which future meaning can be interpreted and negotiated with increasing precision through familiarity. Vygotsky's (1978) discussion on familiarity for developing shared understanding, emphasised that the greater familiarity with their partners, the greater the potential for establishing and maintaining shared meaning within their dialogues. Such commonality and empathy experienced within meaningful relationships has wellbeing and mental health benefits for the children (Herman 1992).

\section{Discussion}

The positioning of the children in ability groups were based on their familiarity of the tools for expressing their understanding in culturally valid forms. Those who were experienced in interpreting adults' meaning and responding appropriately were positioned favourably within the class hierarchy through the school's assessment procedures. Whereas, those whose outside school experiences had not included cultural practices valued by the school, were positioned on the periphery. The overt ordering of individuals appears particularly significant in relation to the theoretical perspectives which emphasise the development of identity based upon negotiating conceptions of oneself from other people's conceptions (Sfard \& Prusak, 2005; Wenger, 2008; London et al., 2014). The children positioned on the periphery of class activity were denied access to the tools required for full participation, thus restricting their trajectories. Whereas, the children positioned favourably were directed towards activity that would maintain conceptions of their competence.

Through regular daily institutional practices of phonics phases, groups and abilities, ability grouping served to routinize and control children's expectations and limitations of themselves. This division of children into their ability groups not only involved a daily memorization and internalization of their status within the hierarchy but was physically reinforced through a thorough daily division of different ability children between and across classes, year groups into the school's different physical spaces. All these early years ability dividing practices and assessments are carefully scrutinized when placing children in year one and two ability groups. A child's initial placement into an ability group has long lasting impacts; $88 \%$ of children placed into sets or streams at age 4 remain in the same groupings until they leave school (Boaler 2005). 
Differing quantities of pedagogic control over the children were noted in each of their varied ability groups. For example, adult control over the low ability children's activity tended to be focussed upon task completion, with directions and instructions given in order to facilitate children's appropriate production of the activities' outcomes. However, by focussing upon completing the task efficiently, opportunities for interactions that may have facilitated the children to gain greater control over their own activities were minimised. By prioritising a passive role in the learning process, the children within the low ability groups were denied access to the opportunities for selfregulation that formed part of the requirement for participation in the other groups and limited their opportunity to express understanding beyond the level ascribed to them. By ascribing a linear 'next step' approach to learning, children's opportunity to demonstrate understanding beyond the 'next step', limited their opportunity to move along the assessment scales, which could have provided evidence of greater progress.

This was in contrast to the the independence in learning shown by the children delete pedagogic interactions between adults and children within the high ability groups which promoted higher order thinking and learner agency. Definitions of learner agency place varying emphases upon conceptions of individual autonomy and the social context in which it is enacted. Explanations of one conception of agency focus on an individual's control over their activity (Blair, 2009), or as an individual's motivation or capacity to act (Mercer, 2011). Whereas alternative depictions of learner agency emphasise the contextual influences upon individual action (Tookey \& Norton, 2003; Lantolf \& Thorne, 2006; Lier, 2008). Lier (2008:1) explains that "agency is not simply an individual character trait or activity, but a contextually enacted way of being in the world". From this view, the experiences of the children within each of the groups provided differing opportunities for developing ways of being. For example, the high ability group were observed to self-regulate their discussion, by individuals and by the group, determining the focus and the progression of their own dialogue and task completion. The children in both the high ability and middle ability groups were afforded a degree of trust and responsibility, to accomplish their given tasks without direct adult control. The control over their activity was less overt, although adult control was still a feature of their activity. However, in the low ability group, the conversation was task-focussed and dominated by the adult, which had the inadvertent effect of minimising the children's own control. This projected a limited, and constrained, capacity for responsibility over their own learning.

The vignettes suggests that the differing pedagogical approaches operated as self-fulfilling prophecies by confirming to the children their fixed ability and their labelled learning identities. Labels of 'ability' were ascribed and reinforced in the different ability groups through varied pedagogical approaches so that the children develop identities and self-concepts based on the school's perceptions of their competences and capabilities. Here the 'self-fulfilling' potential of differing teacher expectations of individuals has been widely explored since the seminal work of Rosenthal \& Jacobson, (1968) in which high expectations of children's intellectual development were reported to have manifested in actual examples of increased intellectual development. Further studies have explored the contextual influences of ability grouping on teacher expectations (Eder 1981), traits which contribute to teachers' expectations of streamed students at whole class level (Rubie-Davies 2010) and teachers' perceptions of children's 'teachability' (Agirdag et al. 2013). This research has suggested that teacher expectation of children's outcomes operates as a selffulfilling prophecy in which children learn to govern and control their abilities according to the 
ability group they are placed in. The restrictions imposed on the low ability children maintained 'peripheral trajectories'(Wenger, 2008), by restricting access to the cultural tools that would be required for full participation. Participation as a low ability member of the class, required conformity, instruction following and passivity. Whereas participation as a middle or high ability member of the class required, and facilitated, articulation, reasoning and self-regulation. The differences between the opportunities provided for the low ability groups, in relation to the other ability groups, indicates some of the influences that act to perpetuate inequity. Through restricted participation, some children may have been denied opportunities to experience the activity that may have enabled them to develop the tools required to become full members.

Considerably more research is needed into the impacts of ability grouping in the early years, especially upon those children placed within low ability groups. However, the findings from this research suggest that school's should prioritise flexible pedagogical approaches to teaching and learning activities, which allow for individual's developmental needs to be suitably met, and enable children to express and develop understanding beyond the level ascribed to them. This could be facilitated through flexibility in grouping practices, which provide opportunities for children to develop relationships, and develop interactional experience with a wide variety of their peers. It is argued that child led play should also be encouraged as it has known wellbeing benefits. 'Play is active, participatory and builds perseverance, cooperation and resilience...through their

play children see themselves as successful, capable and competent learners all of which are key to wellbeing and mental health' (Chivers 2016, 4).

Prioritising and trusting professional dialogue about 'ability', learning and pedagogy in school, involving all adults, would enable misconceptions about ability being fixed, and the interactional repercussions of these misconceptions, to be challenged. Engendering Mastery/Learning Goal orientated environments, which emphasise learning and development, with a decreased emphasis upon performance and evidencing capability within classrooms, would be facilitated by a decrease in the use of children's attainment levels as a measure of teacher and school performance.

\section{References}

Agirdag, O., Van Avermaet, P. and Van Houtte, M. 2013. "School segregation and math achievement: A mixed-method study on the role of self-fulfilling prophecies." Teachers College Record, 115: 1-50.

BERA (2011) "Ethical Guidlines For Educational Research”, London, British Educational Research Association.

Blair, D. V. (2009) "Learner agency: To understand and to be understood", British Journal of Music Education, 26(02), p. 173.

Blatchford, P., Bassett, P., Brown, P. and Martin, C. 2009a "Deployment and Impact of Support Staff in Schools," Department for children, schools and families, ResearchReport No DCSF-RR154. 
Blatchford, P., Bassett, P., Brown, P. and Webster, R. 2009b "The effect of support staff on pupil engagement and individual attention." British Educational Research Journal 355: 661-686.

Blatchford, P., Bassett, P., Brown, P., Martin, C., Russell, A. and Webster, R. 2011. "The impact of support staff on pupils' 'positive approaches to learning' and their academic progress." British Educational Research Journal. 373: 443-464.

Bourdieu, P. (1991) “Language and Symbolic Power”, Thompson, J. B. (ed.), Cambridge, Polity Press.

Bourdieu, P. and Passeron, J.-C. (1990) "Reproduction in Education, Society and Culture", London, SAGE.

Bradbury, A., \& Roberts-Holmes, G. (2018) Grouping in Early Years and Key Stage 1: A Necessary Evil? London: National Education Union. Retrieved from https://neu.org.uk/policyand-campaigns/policy-posts/ability-grouping-early-years-and-key-stage-1

Boaler, J. 2005. “The 'Psychological Prisons' from which They Never Escaped: the role of ability grouping in reproducing social class inequalities." FORUM, 47 (2): 125-134.

Chivers, D. 2016. "Playing to Learn: A guide to child-led play and its importance for thinking and learning” London, ATL Publications

Eder, D. 1981. "Ability Grouping as a Self-Fulfilling Prophecy: A Micro-Analysis of TeacherStudent Interaction.” Sociology of Education, 54:151-162.

Ireson, J. and Hallam, S. 2001 Ability grouping in Education. London. Paul Chapman Publishing.

Lantolf, J. P. and Thorne, S. L. (2006) 'Sociocultural Theory and Second Language Learning', In van Patten, B. and Williams, J. (eds.), Theories in second language acquisition, Erlbaum, pp. 201-224.

Lave, J. and Wenger, E. (1991) Situated learning: Legitimate peripheral participation, Learning in doing, Cambridge, Cambridge University Press.

Lier, L. van (2008) 'Agency in the classroom', In Lantolf, J. P. and Poehner, M. E. (eds.), Sociocultural theory and the teaching of second languages., London, Equinox.

London, B., Ahlqvist, S., Gonzalez, A., Glanton, K. V. and Thompson, G. a. (2014) 'The Social and Educational Consequences of Identity-Based Rejection', Social Issues and Policy Review, 8(1), pp. 131-166.

Lupton, D. 2016. The quantified self. Cambridge. Polity Press. 
Marks, R. 2016. Ability-grouping in primary schools: Case studies and critical debates. Northwich, Critical Publishing.

Mercer, N. (1995) The Guided Construction of Knowledge: Talk Amongst Teachers and Learners, Clevedon, Multilingual Matters Ltd.

Mercer, N. (2000) Words \& Minds, London, Routledge.

Mercer, N. 2008 "Talk and the Development of Reasoning and Understanding." Human Development, 511: 90-100.

Mercer, S. (2011) 'Understanding learner agency as a complex dynamic system', System, Elsevier Ltd, 39(4), pp. 427-436.

Moss, P. 2019. Alternative Narratives in Early Childhood: An Introduction to Students and Practitioners. Routledge, London.

Muijs, D. and Reynolds, D. 2003 "The effectiveness of the use of learning support assistants in improving the mathematics achievement of low achieving pupils in primary school." Educational Research, 453: 219-230.

Parsons, S. and S. Hallam. 2014. "The impact of streaming on attainment at age seven: evidence from the Millennium Cohort Study". Oxford Review of Education 40(5): 567-589.

Plaks, J. E., Stroessner, S. J., Dweck, C. S. and Sherman, J. W. 2001 "Person theories and attention allocation: Preferences for sterotypic versus counterstereotypic information." Journal of Personality and Social Psychology. 806: 876-893.

Porath, M. and Bruner, J. 2000 "The Culture of Education," Canadian Journal of Education / Revue canadienne de l'éducation. 253.

Rogoff, B. (2008) 'Observing Sociocultural Activity on Three planes: Participatory Appropriation, Guided Participation, and Apprenticeship', In Hall, K., Murphy, P., and Soler, J. (eds.), Pedagogy and Practice Culture and Identities, London, SAGE Publications Ltd.

Rosenthal, R. and Jacobson, L. 1968 "Pygmalion in the classroom." The Urban Review 16-20.

Rubie-Davies, C. M. 2010. "Teacher expectations and perceptions of student attributes: Is there a relationship?" The British journal of educational psychology. (80). 121-35.

Sfard, A. and Prusak, A. (2005) 'Telling identities: In search of an analytic tool for investigating learning as a culturally shaped activity', Educational Researcher, 34, pp. 14-22. 
Taylor, B., B. Francis, L. Archer, J. Hodgen, D. Pepper, A. Tereshchenko and M. Travers. 2016. "Factors deterring schools from mixed attainment teaching practice." Pedagogy, Culture \& Society: 1-16.

Tookey, K. and Norton, B. (2003) Learner Autonomy as Agency in Sociocultural Settings, Palfreyman, D. and Smith, R. (eds.), Learner autonomy across cultures Language education perspectives, Basingstoke, Palgrave Macmillan.

Vygotsky, L. S. 1978 Mind in Society: The Development of Higher Psychological Processes, Cole, M., John-steiner, V., Scribner, S., and Souberman, E. eds., London, Harvard University Press.

Vygotsky, L. (1986) Thought and Language, Kozulin, A. (ed.), London, MIT Press.

Weale, S. (2017) “More primary school children suffering stress from SATs” Retrieved 23 September 2017, from https://www.theguardian.com/education/2017/may/01/sats-primaryschool-children-suffering-stress-exam-time

Webster, R., Blatchford, P., Bassett, P., Brown, P., Martin, C. and Russell, A. 2011 "The wider pedagogical role of teaching assistants," School Leadership \& Management, 311, 3-20.

Wenger, E. (1998) Communities of Practice: Learning, Meaning, and Identity, Learning in doing, Cambridge, Cambridge University Press.

Wenger, E. (2008) 'Identity in Practice', In Hall, K., Murphy, P., and Soler, J. (eds.), Pedagogy and Practice Culture and Identities, London, SAGE Publications Ltd.

Wertsch, J. V (1985) Vygotsky and the social formation of mind, London, Harvard University Press.

Wertsch, J. V. (1991) Voices of the Mind, London, Harvard University Press.

Wood, D., Bruner, J. S. and Ross, G. (1976) 'The role of tutoring in problem solving.', Journal of Child Psychology and Psychiatry, 17(2), pp. 89-100. 